\title{
La imagen de Dios en el hombre en la teología de lo Sobrenatural de Henri de Lubac
}

\author{
Sergio Cobo \\ FACULTAD DE TEOLOGÍA \\ PONTIFICIA UNIVERSIDAD CATÓLICA DE CHILE \\ SACOBO@UC.CL
}

Resumen: H. de Lubac es conocido por su teología de lo Sobrenatural, mediante la cual ha querido superar el abismo que se mantuvo entre la naturaleza y lo Sobrenatural. Para la elaboración de esta teología el autor ha recurrido a la tradición católica. En este proceso de elaboración, el concepto bíblico antropológico "creado a imagen de Dios", fuertemente arraigado en la teología cristiana desde la Escritura hasta nuestros días, ha tenido un lugar fundamental. Este artículo busca mostrar la presencia de este concepto en la teología lubaciana.

Palabras clave: Henri de Lubac, Sobrenatural, imagen de Dios, teología siglo XX.

Abstract: H. de Lubac is known for his theology of the supernatural, through which he has sought to overcome the abyss that remained between nature and the supernatural. For the elaboration of this theology, the author has resorted to the Catholic tradition. In this process of elaboration, the biblical-anthropological concept "created in the image of God", strongly rooted in Christian theology from Scripture to the present day, has had a fundamental place. This article seeks to show the presence of this concept lubacian theology.

Keywords: Henri de Lubac, Supernatural, image of God, XX century theology. 


\section{INTRODUCCIÓN}

Henri de Lubac ha sido reconocido como el teólogo de lo Sobrenatural. Su obra Surnaturel (1946) y las obras sobre el tema de lo Sobrenatural que le siguieron ${ }^{2}$ significaron un importante vuelco en la antropología y la teología durante el siglo XX. Con ellas nuestro autor se propuso restablecer el contacto entre la teología católica y el pensamiento contemporáneo $^{3}$. Esta inquietud se gesta en los tiempos de estudiante jesuita, pues De Lubac experimenta la insuficiencia de la teología moderna frente a las interrogantes del hombre del siglo $\mathrm{XX}^{4}$ y al riesgo que suponía un humanismo que amenaza con la destrucción de la persona humana 5 .

Este tema no fue para De Lubac una cuestión marginal. De Lubac ve incluido en este problema toda la antropología todo el misterio del hombre y de Dios ${ }^{6}$. Veía este tema presente en el fondo de las discusiones del pensamiento cristiano con la increencia moderna y como el nudo del problema del humanismo cristiano ${ }^{7}$. El teólogo francés va a buscar respuestas en el mismo pensamiento cristiano considerando su desarrollo en la tradición ${ }^{8}$.

1 De Lubac, H. Surnaturel. Étude historiques (Paris: Lethielleux/Groupe DDB, 2010).

2 De Lubac, Le Mystère du Surnaturel (1965); Augustinisme et Théologie moderne (1965); Petite Catéchèse sur nature et grâce (1980).

3 De Lubac, H. Mémoire sur l'occasion de mes écrits (Namur: Culture et vérité, 1989), 34.

4 Es interesante cómo influyó en esto la experiencia de la guerra para De Lubac y su generación: es la constatación de la impotencia de la apologetica clásica y la necesidad de una respuesta adecuada a las preguntas del hombre en la época que vivían (cfr. Fouilloux, É. Une Église en quête de liberté. La pensée catholique française entre modernisme et Vatican II (1914-1962) (Paris: Desclée, 2006), 175-176 ; cfr. 215).

5 Cfr. De Lubac, H. Le drame de l'humanisme athée (Paris: Spes, 1965), 6.

6 Cfr. De Lubac, H. Surnaturel, 6.

7 Cfr. De Lubac, H., Mémoire, 33.

8 "De Lubac presenta el perfil de su obra con estas palabras: ‘... mi esfuerzo ha consistido fundamentalmente, aun cuando he debido tomar parte en las luchas de nuestro tiempo, en hacer conocer mejor y, por tanto, también juzgar mejor y amar mejor los tesoros de la gran tradición católica...' ". Citado en R. Gibellini, La teología del siglo XX. Trad. por Rufino Velasco (Santander: Sal Terrae, 1998), 196. 
En esta búsqueda ha sido clave la idea del "hombre creado a imagen de Dios" . Comprender el pensamiento lubaciano implica reconocer en sus fundamentos la teología de la imagen, recogida por nuestro autor desde la patrística y la teología escolástica. De este modo, acercarse a la teología de H. de Lubac teniendo como clave la "imagen” no es solo posible, sino necesario. Considerada la teología de la imagen como un aspecto fundamental en el pensamiento de De Lubac, su misma dinámica lleva a preguntarse por la imagen de Dios que está a la base. Encontraremos ahí al Dios Trinitario y, particularmente, al Verbo encarnado.

Comenzamos por mostrar muy brevemente expresiones del pensamiento neoescolástico ante el que De Lubac reacciona. Luego veremos los trazos generales de la respuesta lubaciana y los elementos de la teología de la imagen para poder así verificar el lugar que ocupa la idea de "hombre creado a imagen de Dios" en el pensamiento de H. de Lubac. Terminamos por proyectar sintéticamente cómo la teología de lo Sobrenatural fundada en la "imagen" nos lleva a pensar en la imagen de Dios que da sustento a esta teología.

\section{LA TEOLOGÍA MODERNA Y LA NATURALEZA PURA}

Santo Tomás de Aquino define que el hombre, en tanto es naturaleza racional, tiene como fin propio y natural la visión de Dios ${ }^{10}$. Y en la Suma Teológica explicará que "la imagen de Dios en el alma (del hombre) se tiene en cuanto que es llevada o puede ser llevada a Dios" ${ }^{11}$, con lo que

9 Domingo García G. nos ha ofrecido una interesante lectura de una visión de Dios en Henri de Lubac a partir de la dimensión antropológica “imagen de Dios” que el mismo De Lubac utiliza como clave en Le drame de l'humanisme athée y en Sur les chemanis de Dieu. Su estudio muestra la relevancia de considerar la imagen de Dios impresa como sello en el hombre ante el trágico malentendido del ateísmo (o anti teísmo, como dirá De Lubac) que visualiza a Dios como un competidor del hombre (cfr. García, D. «Conocer a Dios en su Imagen. Una lectura de Henri de Lubac», Scripta Theologica 49 (2017), 371-402).

10 Santo Tomás de Aquino, Suma contra Gentiles, 1.3, c.25, n.14. De hecho, Tomás nunca habla de "naturaleza pura" (Cfr. De Lubac, H., Augustinisme et théologie moderne (Paris: Cerf. 1965), 262; Rondet, H., «Nature et surnature dans la théologie de saint Thomas d'Aquin", Recherches Sciences Religieuses 33 (1946), 64 ; Rondet, H. "Le problème de la nature pure et la théologie du XVIe siècle», Recherches Sciences Religieuses 35 (1949), 485)

11 Tomás de Aquino, Suma Teológica I, q.93, a.8, resp. Cfr. Suma Teológica III, q.9, a.2, resp. 
define al hombre como capaz de Dios. Sin embargo, desde el siglo XVI, e incluso antes, se fue extendiendo la idea de que el Aquinate sostenía la existencia de una doble finalidad para el ser humano: una natural y otra sobrenatural; esto a partir de la hipótesis de la naturaleza pura ${ }^{12}$.

Dionisio el Cartujo (+1461) es quien primero sostiene esta doble finalidad. Pero él no pretende interpretar sino contradecir a Tomás a partir de la naturaleza pura. Lo refuta exprofesso: hay en el hombre un deseo natural de ver a Dios con un conocimiento natural y perfecto en su orden. Este deseo se colmaría, no en esta vida, sino en la otra ${ }^{13}$.

A quien se atribuye la introducción de la naturaleza pura como clave de comprensión del hombre es a Tomás de Vio Cayetano, pues su influencia fue decisiva al respecto. Cayetano, a la inversa de Dionisio, pretende hacer una interpretación auténtica de Tomás. Pero, al realizar esta interpretación, concibe el sobrenatural de manera que termina por relegarlo al ámbito de lo milagroso, es decir, de una excepción arbitraria. Su definición de naturaleza le debe más al aristotelismo que al pensamiento cristiano y se rige por un axioma del Estagirita bastante conocido en el siglo XVI: "si la naturaleza diese al cielo la inclinación para un movimiento progresivo, daría también los medios para ese movimiento" ${ }^{14}$.

12 No hay en la obra de Tomás una afirmación acerca de la posibilidad de una creación del hombre sin ser "elevado" al orden sobrenatural, pero la insistencia del Aquinate sobre lo indebido del don del dicha elevación en relación a la naturaleza del hombre podía llevar a pensar que crear al ser humano no significa necesariamente la comunicación de las perfecciones de orden sobrenatural (cfr. Ladaria, L. F., «Nature et Surnaturel». En V. Grossi et al. Histoire des dogmes: L'homme et son salut vol. II. (Sous la direction de Sesboüé, B. Paris: Desclée, 1995), 384-385).

13 Cfr. de Lubac, H., Augustinisme et théologie moderne, 237.

Este autor resulta relevante pues De Lubac dirá que pudo haber influido en Cayetano a través de la formación de éste en Padua. Esta es una hipótesis para explicar que Cayetano haya aceptado y sostenga sin dudas la naturaleza pura y la distinción de órdenes.

14 Si natura dedisset caelis inclinationem ad motum progressivum, dedisset etiam instrumenta ad talem motum (Aristóteles, II de Caelo, cap. VIII, n.8; citado en Thomae Aquinatis. Opera omnia, iussu impensaque Leonis XIII. P.M. Cum commentariis Thomae de Vio Caietani ordinis predicatorum: Pars prima theologiae a questione I ad questione XLIX. vol. 4. (Romae: Typographia polyglotta, 1888). http://archive.org/ stream/operaomniaiussui04thom\#page/n5/mode/2up, q.12, a.1, n.IX.). 
A partir de este axioma Cayetano interpreta el texto de Tomás entendiendo que la naturaleza tendría un fin natural proporcionado a sus fuerzas, de lo contrario sería vana. Esto mismo lo lleva a afirmar que un fin sobrenatural no pertenecería a la naturaleza humana como elemento constitutivo: "No parece verdadero que el intelecto creado naturalmente desee ver a Dios: puesto que la naturaleza no concede la inclinación a algo a que toda la fuerza de la naturaleza no puede conducir" ${ }^{15}$. Se irá cambiando la "imagen" por la "naturaleza" según la definición aristotélica ${ }^{16}$.

Después de Cayetano, el uso de la hipótesis de naturaleza pura no se extiende ni masiva ni definitivamente en los planteamientos teológicos del s. XVI. Varios teólogos no acudieron a ella, o lo hicieron tangencialmente con el fin de responder a errores de la época ${ }^{17}$.

Quien sí contribuyó decisivamente a la instalación del concepto de naturaleza pura en la teología fue Francisco Suárez ${ }^{18}$. Para asegurar la gratuidad de la gracia divina, Suárez expresa con mayor nitidez y precisión que quienes lo precedieron qué es la naturaleza pura y plantea su concepción del hombre a partir de esta definición. Con este fin, Suárez define claramente el estado de naturaleza pura:

El estado de naturaleza pura incluye y requiere dos [postulados]: uno positivo, evidentemente, para que en él la naturaleza humana cuente con las perfecciones esenciales, todas las facultades naturales y el concurso de la providencia divina naturalmente debida a ella; otro negativo, que, evidentemente, nada tenga sobreańadido la naturaleza, ni debido a ella, ni malo, ni bueno, es decir, que no tenga ni pecado, ni

15 Thomae Aquinatis, Summa Theologiae I q.12, a.1, n.IX.

16 Cayetano señala que en el hombre existe el deseo de ver a Dios, pero como causa de las cosas (Cfr. Thomae Aquinatis, Summa Theologiae I q.12, a.1, n. VIII.), y no en su esencia (an est, no quid est). Mientras Tomás señala: "todo intelecto desea naturalmente ver la sustancia divina (omnis intellectus naturaliter desiderat divinae substantiae visionem; Tomás de Aquino, Suma Contra Gentiles, 1.3, c.57.)", Cayetano afirmará expresamente lo contrario: "no parece verdadero que el intelecto creado desee naturalmente ver a Dios (non videtur verum, quod intellectus creatus naturaliter desiderat videre Deum; Thomae Aquinatis, Summa Theologiae I q.12, a.1, n.IX.)".

17 Esto lo podemos ver en autores como Domingo de Soto (1499-1560), Francisco de Toledo (1533- 1596) y Roberto Belarmino (1542-1621) (cfr. de Lubac, H., Augustinisme et théologie moderne, 153. 173-174. 194 ; Rondet, H., "Le problème de la nature pure», 510).

18 Avec François Suárez, elle va faire un pas de géant (De Lubac, H., Augustinisme et théologie moderne, 194). 
reato de la pena, que es una consecuencia [del pecado], ni esté afecta con algunos dones de la gracia, o perfecciones no debidas a la naturaleza ${ }^{19}$.

El objetivo de Suárez es salvar la gratuidad de la gracia; para eso describe y considera la naturaleza pura como un estado factible del hombre y posible de pensar en toda etapa de la existencia humana ${ }^{20}$. En este esquema, dado que la gracia no tiene correlato alguno en la estructura de la naturaleza del hombre, y sin perjuicio que Suárez afirma que el hombre ha sido creado en gracia, no repugna a la potencia absoluta de Dios haberlo creado in puris naturalibus y ordenado a un fin proporcional a este estado $^{21}$.

Se pierde aquí la vinculación entre creación y visión sobrenatural (salvación), pues esta última es para el hombre creado simple y absolutamente sobrenatural. El hombre creado se puede comprender en sí mismo, sin referencia a Dios, aunque de hecho, históricamente, y no como constitutivo suyo, el hombre tenga como fin a Dios.

La teología construida sobre la hipótesis de la naturaleza pura llevó a un empobrecimiento de la comprensión del hombre y de su relación con Dios. Un hombre que tiene un fin natural que puede alcanzar por sí mismo, un fin que perfecciona su naturaleza y al cual la visión de Dios le es naturalmente extrańa, y que puede vivir y ser feliz (aunque sea con una felicidad natural), sin Dios. De este modo, esta teología sugiere una fractura en la realidad que significa poner en entredicho, por una parte la unidad del plan de Dios, es decir, la unidad entre la creación y la redención; y, por otra, la relación única que el hombre tiene con Dios por la cual es el único ser abierto personalmente a la trascendencia. En resumen, el hombre deja de ser visto y comprendido como "imagen de Dios".

\section{LA RESPUESTA DE H. DE LubaC}

De Lubac responderá a estas propuestas recurriendo a la tradición católica. En concreto, el proyecto de H. de Lubac, su teología de lo Sobrenatural, quiere ser una vuelta al augustinismo, corriente dejada de lado a

19 SuÁrez, F. De gratia. Opera omnia vol. VII. (Parisiis: Ludovicum Vives (ed.), 1856), Proleg. IV, c.I, n.3.

20 Cfr. SuÁrez, F. De gratia, Proleg. IV, c.I, n.5.

21 Cfr. SuÁrez, F. De gratia, Proleg. IV, c.I, n.15. "añado que la beatitud eterna [...] está sobre la naturaleza del hombre, y es preparada por la providencia sobrenatural" (Suárez, F. De gratia, Proleg. IV, c.I, n.9 ; cfr. n.11) 
causa de malas interpretaciones que se han hecho de ella, sobre todo a partir de Bayo y Jansenio. A juicio de nuestro autor, la corriente conocida como augustinismo no se identifica únicamente con la teología de Agustín. También considera que esta tradición se ha constituido con la valiosa reflexión de los padres griegos ${ }^{22}$. Esto significará volver a la tradición y, en diálogo con ella, asumiendo los cuestionamientos y búsquedas del s. XX, elaborar una teología que exprese la verdad cristiana sobre el hombre con el fin de recuperar la "paradoja fundamental que constituye la relación del hombre con Dios"23.

Éric de Moulins-Beaufort destaca tres conceptos en torno a los cuales gira la antropología lubaciana: espíritu, misterio e imagen ${ }^{24}$. Aunque De Moulins-Beaufort justifica con una detallada argumentación que el término espíritu es el que predomina a la hora de hablar del hombre, la relación entre estos términos es tan estrecha, que no se entiende uno $\sin$ los otros ${ }^{25}$. Si bien De Lubac no ha mostrado sistemáticamente qué entiende en concreto por imagen y qué peso tiene en el desarrollo de su pensamiento, será posible determinar que, aunque junto a los otros dos conceptos, está en el núcleo de su pensamiento sobre el hombre.

22 En la tercera parte de Surnaturel, Aux origines du mot surnaturel, De Lubac explica, con diversas citas y referencias, que los padres griegos consideran que lo que es natural al hombre es una vida semejante a la naturaleza divina, alcanzada como don de Dios. Damos aquí solo dos referencias que sintetizan la enseñanza de los padres sobre este punto: De Lubac, H., Surnaturel, 367-368, 377-379.

23 E. Gilson, Philosophie et incarnation selon saint Augustin, (Montreal, 1947), 9; en De Lubac, H., Le mystère du surnaturel, Euvrés Complètes vol XII. (Paris: Cerf. 2009), 38.

24 Cfr. De Moulins-Beaufort, É., Anthropologie et Mystique Selon Henri De Lubac: "l'esprit de L'homme», ou la présence de Dieu en L'homme. (Paris: Cerf. 2003), 35 y 327.

También Georges Chantraine señala "espíritu” como palabra clave de la antropología de H. de Lubac (cfr. Chantraine, G., «L'actualité de l'œuvre du cardinal Henri De Lubac». Communio 24 (1999), 117-118). Pero no es posible comprender este concepto sino en su estrecha relación con el de «imagen de Dios» (cfr. Chantraine, G., «Le surnaturel, discernement de la pensée catholique selon Henri de Lubac». Revue Thomiste 101 (2001), 33 y 40).

25 Misterio, imagen, espiritu... Estas tres palabras evocan el abismo, su concatenación nos hacen comprenderlo mejor: abismo de la Presencia en el hombre del Dios misterioso, misterio de la intimidad del Modelo a su imagen, interioridad inagotable del espiritu vuelta a poner en él mismo... El espiritu es la impresión que Dios hace en el hombre de su imagen y que constituye al hombre (de Moulins-Beaufort, É., Anthropologie et mystique selon Henri de Lubac, 491.858 (la traducción es del autor del artículo); cfr. De Moulins-Beaufort, É., Anthropologie et mystique selon Henri de Lubac, 869). 
De Lubac quiere responder a un abismo que se ha producido al pensar la relación del hombre con Dios y su vida humana cotidiana, histórica, contingente. Así De Lubac constata durante el s. XX, que el discurso teológico se ha vuelto irrelevante y se produce un empobrecimiento de su aporte a la vida cristiana y, en general, a la vida del hombre ${ }^{26}$; además, no ofrece una respuesta a los desafíos que presentan otros pensamientos en el s. $\mathrm{XX}^{27}$. Y la clave para De Lubac es que: "hemos olvidado en él (hombre) 'la imagen viva del Dios vivo" 28 .

\section{El aporte de la teología de la imagen a la teología del Sobrenatural}

La respuesta lubaciana se construye como proyección de la antropología cristiana, la cual encuentra sus fundamentos en el concepto bíblico de imagen creada $^{29}$. La condición de criatura refiere constitutivamente al hombre a Dios, pues ser criatura significará depender de Él. Pero también nos dice que es imagen de Dios, cuestión que sólo pertenece al hombre. Por tanto, no solo depende ontológicamente de Dios, sino que está llamado y tiene su fin en participar de la vida divina, para lo cual ha sido dotado de un dinamismo espiritual:

Exigencia puesta en el hombre por el Creador, cuando lo hizo "a su imagen", asignándole como ideal y como término "su semejanza".

26 De Lubac, reconociendo el esfuerzo de la apologética para preservar la fe, señala que sus planteamientos no tocan el corazón del hombre ni responden a sus aspiraciones y experiencias concretas (Cfr. De Lubac, H., Augustinisme et théologie moderne, 315; cfr. "Causes internes de l'atténuation et de la disparition du sens d Sacré»; en De Lubac, H., Théologie dans l'histoire. Vol II. (Paris: Desclée, 1990), 24-30).

27 Cfr. De Lubac, H., Le mystère su surnaturel, 15-16.

28 Cfr. De Lubac, H., Augustinisme et théologie moderne, 257.

29 Explicando que la dualidad propuesta por la teología moderna se consolida como la reacción a los errores de Bayo, señala que dicha concepción no ha sido acogida por la Iglesia, y se opone al Tradición viva de la Iglesia. Pour les Pères de l'Ėglise, l'homme, créé à l'image de Dieu, c'est-à-dire avec ces prérogatives divines que sont la raison, la liberté, la immortalité, la domination de droit sur la nature, est fait en vue de la ressemblance de Dieu, qui est la perfection de cette image, c'est-à-dire qu'il est destiné à vivre éternellement en Dieu, à entrer dans le mouvement interne de la Vie trinitaire et à y entrainer avec lui toute la création. De même pour saint Thomas, il y a dans la nature humaine comme telle, parce que spirituelle, un désir, un appétit de nature, indice d'une ordination ontologique, qui ne se saurait demeurer toujours insatisfait sans que l'auvre du Créateur soit manquée, et qui ne peut être satisfait autrement que par la vision même de Dieu face à face (De Lubac, H., «Causes internes», 20). 
Desde entonces, este término funciona en nuestra naturaleza y este ideal trabaja en nuestra libertad ${ }^{30}$.

Una mirada al lugar que ha tenido el concepto de imagen en los pensadores cristianos durante la historia nos permite determinar algunos elementos comunes que dan la posibilidad de mostrar cómo se ha entendido por "ser imagen creada de Dios" al hablar del hombre en el cristianismo ${ }^{31}$. Podemos resumir así estos elementos:

1. Ser imagen creada es constitutivo del hombre.

2. Esta imagen es el sello que Dios ha puesto en el hombre, el cual expresa que éste es una criatura racional, dotada de inteligencia, voluntad y libertad. Es decir, el hombre está dotado de la capacidad de conocerse y de transcenderse para entrar en relación. Es un sujeto espiritual.

3. Ser imagen de Dios y, por tanto, criatura espiritual, significa que el hombre está naturalmente abierto al Absoluto. Esto se traduce en el deseo de la unión con Dios que es su única perfección. Por eso, la imagen está en tensión hacia la semejanza con Dios, que expresa la posesión del fin prometido.

4. Por fin, existe un vínculo orgánico de la imagen y la semejanza, lo que nos habla de un proceso y por tanto de un desarrollo del hombre hacia la plenitud. Esto apunta al carácter histórico de la existencia humana $y$, también a la distinción de órdenes entre imagen y semejanza, por lo que, sin exigirla, espera la acción gratuita de Dios en la vida del hombre, a la que el mismo hombre responde con su colaboración. El hombre es capax Dei y por eso mismo es capax gratiae; su comunión de vida se consuma en la eternidad, pero tiene su comienzo en la historia.

Intentaremos ahora relevar estos elementos en el pensamiento de nuestro autor.

30 De Lubac, H., Surnaturel, 490.

31 En la investigación presentada en la Universidad Católica de Chile para obtener el grado de doctor en teología, la cual será publicada próximamente, hemos recogido desde los textos citados por De Lubac de 5 autores (Orígenes, San Gregorio de Nisa, San Agustín, Santo Tomás de Aquino y San Buenaventura) los elementos de la teología de la imagen. 


\section{LA CREACIÓN, DON INTERIOR AL HOMBRE}

De Lubac no deja de lado la definición de una naturaleza consistente, pero él asume la naturaleza como una realidad análoga ${ }^{32}$. No se dice de la misma manera naturaleza cuando se habla de un vegetal, de un animal o del hombre. El hombre es "naturaleza singular y paradojal", puesto que siendo parte de la creación, está abierto a la trascendencia: "es la situación 'de un espíritu que deviene el sujeto y el agente de un acto de conocimiento para el cual no está equipado naturalmente, y que debe así alcanzar su plenitud sobrepasándose" 33 .

De Lubac cambia la perspectiva para acercarse a la realidad del hombre. El hombre creado no debe responder a una definición rígida de naturaleza, a la que Dios debería atenerse. En ese caso, si ese hombre tuviera que ser creado con un fin sobrenatural, Dios estaría obligado a otorgárselo. El hombre que existe es el hombre que Dios ha creado libremente, ya que, como señala Agustín: "la voluntad de tan grande Creador es la naturaleza de toda realidad creada" ${ }^{4}$. Así, en palabras de Tomás de Aquino, Dios no crea solo el ser, sino la esencia (quididad) misma es creada, es decir, la naturaleza del hombre es fruto de la libre voluntad de Dios, y ese hombre es imagen de Dios ${ }^{35}$ : "Por eso todo espíritu, esté o no en un cuerpo, goza de ciertas prerrogativas que haciéndolo "imagen" del Creador, lo hacen al mismo tiempo superior a todo el orden del cosmos" 36 .

Dos elementos son importantes a este respecto: que la creación es un don "interior" al hombre ${ }^{37}$ y lo constituye como un ser orientado a Dios, es decir, la creación es proyecto de comunión. Efectivamente, la creación, por la cual el hombre es, lo define permanentemente como criatura, y, en concreto, como una criatura constitutiva y totalmente referida a Dios. Esto significa que la llamada que Dios hace al hombre tiene desde su

32 Cfr. De Moulins-Beaufort, Anthropologie et mystique, 439.

33 De Lubac, H., Le mystère du Surnaturel, 136.

34 "Voluntas tanti Creatoris, conditae rei cuiusque natura est» (San Agustín de Hipona, De civitate Dei, 1. 21, c. 8, n. 2; en De Lubac, H., Le mystère du Surnaturel, 41).

35 Santo Tomás de Aquino, De potentia, q.3, a.5, ad. 2. En De Lubac, H., Le mystère du Surnaturel, 284.

36 De Lubac, H., Le mystère du Surnaturel, 138.

37 Cfr. de Lubac, H., Le mystère du Surnaturel, 107-108. 
comienzo un correlato ontológico en su ser creado: "mi destinación es cosa ontológica" ${ }^{38}$. Así, el hombre es una naturaleza espiritual, porque es imagen de Dios.

Por esta razón, De Lubac dice que el hombre creado a imagen de Dios es constituido espiritu, es decir, deseo de Dios ${ }^{39}$. No se entiende su ser sin su destinación. Se descubre en el hombre una dependencia constitutiva, por cuanto lo que él es se comprende y se vive en relación a Dios que lo crea, lo mantiene y lo destina gratuitamente a la vida de comunión con Él. Esta dependencia no es comprendida como limitación, sino como condición, característica del ser del hombre. Es el camino de su propia plenitud, pues su grandeza está en la comunión con Dios.

Ser imagen significa para el hombre dependencia de Dios y apertura a Él. De esta manera, hay ya en el hombre una realidad que permite que pueda no solo conocer a Dios, sino, de algún modo, reconocerlo y, en eso, reconocerse $\mathrm{e}^{40}$. La realidad humana queda constituida por su pertenencia a la creación y su apertura a lo eterno. No son dos realidades del hombre, sino dos dimensiones constitutivas de lo que el hombre es, que hacen referencia a la distinción natural y sobrenatural:

Si hay en nuestra naturaleza un deseo de ver a Dios, eso no puede ser sino porque Dios quiere para nosotros este fin sobrenatural que consiste en verle $[\ldots]$ De esta manera este deseo no es otra cosa que su llamada ${ }^{41}$.

\section{Creado para la comunión}

De Lubac dice "distinguir para unir" ${ }^{2}$, es decir, la distinción está en orden a la unión. Entonces, si Dios crea una criatura espiritual distinta de él, entendida la desproporción entre Creador y criatura, ha sido para invitarla a la comunión. Ser imagen de Dios es estar orientado a Dios, pero no según una lógica de fuerzas ciegas o de un proceso natural necesario sino

38 De Lubac, H., Le mystère du Surnaturel, 90.

39 De Lubac, H., Surnaturel, 482.

40 Cfr. De Lubac, H., Sur les chemins de Dieu, 16. 93-94; cfr. É. de Moulins-Beaufort, Anthropologie et mystique selon Henri De Lubac, 139.

41 De Lubac, H., Surnaturel, 486-487.

42 Cfr. De Lubac, H., Le mystère du Surnaturel, 55. 
en la interacción de libertades: el hombre es un sujeto libre y autónomo ante el fin al que ha sido llamado ${ }^{43}$.

La libertad tiene un lugar central en el pensamiento de H. de Lubac, pues en ella se fundamenta el valor de la respuesta del hombre a la llamada divina y el peso de su responsabilidad frente a ella ${ }^{44}$. Es condición de posibilidad de la dinámica expresada en el dúo imagen y semejanza, tomado de los Padres de la Iglesia ${ }^{45}$. La realidad de la imagen impresa en el hombre por la creación lo constituye persona y la compresión delubaciana en este punto responde a esa relación ${ }^{46}$.

Ahora bien, la superación de la distancia, si podemos llamarla así, entre la imagen y la semejanza, entre el hombre creado y el fin al que está llamado, no es el fruto solo del esfuerzo humano. La dinámica según la que el hombre alcanza ese fin es la metanoia. Esta metanoia significa entrega, abandono e incluso muerte. De Lubac ha insistido que el fin del hombre no es una sequela creationis, sino una realidad radicalmente distinta de su naturaleza creada. La consideración de la realidad sobrenatural de este fin, nos conducirá a afirmar que éste "no corona y no acaba los esfuerzos del hombre sino porque los somete antes que nada a un vuelco radical" ${ }^{\prime 7}$. En efecto, la perfección del hombre no es la consecuencia del despliegue de su dinamismo natural, sino el fruto de una "unión transformante" ${ }^{48}$, que supone la diferencia cualitativa entre lo natural y lo sobrenatural ${ }^{49}$. Esto supone también un nuevo principio respecto de lo natural. De Lubac lo

43 Cfr. De Lubac, H., Surnaturel, 490. De Lubac afirma que la libertad de todo espíritu creado es un punto capital y necesario para la antropología cristiana (cfr. Henri De Lubac, Jacques Maritain, Correspondance et rencontres. Paris: Cerf. 2012, 54).

44 Cfr. De Lubac, H., Surnaturel, 185-321. La libertad es el signo de dignidad del hombre en tanto ser espiritual, como nos explica De Moulins-Beaufort (cfr. É. De Moulins-Beaufort, Anthropologie et mystique selon Henri De Lubac, 341; cfr. De Lubac, H., Surnaturel, 189).

45 Cfr. De Lubac, H., Le mystère du Surnaturel, 54-55.

46 Cfr. De Lubac, H., Le mystère du Surnaturel, 91; «Petite Catéchèse sur nature et grâce». Euvres Complètes vol. XIV. (Paris: Cerf, 2013), 219.

47 H.U. von Balthasar, Théologie de l'histoire, (trad. Givord, 1955), 167; en De Lubac, Le mystère du Surnaturel, 51.

48 De Lubac, H., Le mystère du Surnaturel, 51.

49 De Lubac confirmará este idea en el futuro (cfr. De Lubac, H., «Petite Catéchèse», 235). 
entiende como el principio de vida que representa la gracia santificante ${ }^{50}$, la cual es un don ${ }^{51}$. De esta forma, la dinámica del espíritu del hombre, su deseo, es entrega y abandono, es una total confianza en Dios. En esta muerte se expresa de manera dramática la paradoja del hombre.

Aunque la metanoia sea una cierta muerte, no significa aniquilación, sino entrega confiada, donación de amor. Por eso la pretensión cristiana de la comunión con Dios, de la vida eterna, no es una audacia prometeica, "no es en absoluto presunción" de alcanzar algo que solo Dios puede dar: "ella es fiducia" 52 . Esta muerte es, entonces, el acto de una audaz confianza en la llamada y el amor de Dios ${ }^{53}$. El cristiano tiene conciencia de la trascendencia divina, pero también descubre que su deseo es la atracción que Dios ha puesto en su ser creado y que es una disposición constitutiva que no alcanza su fin siguiendo únicamente su movimiento, sino que se colma en la entrega total a la acción gratuita de Dios a favor del hombre.

\section{IMAGEN Y ACCIÓN GRATUITA DE Dios}

Por sí mismo, el hombre no solo no alcanza su fin, sino que no reconoce ese fin. En este sentido, el hombre está totalmente referido a la relación con Dios, de modo que si Dios no se manifiesta en su existencia, el hombre no puede descubrir la profundidad y orientación de su dinamismo: "Es la libre voluntad del donador la que despierta el deseo en aquel que quiere alcanzar" ${ }^{54}$.

Si bien el deseo de Dios late en el hombre, es por la llamada personal de Dios que el hombre es despertado a la conciencia de este deseo ${ }^{55}$. El hombre es un misterio para sí, pues su existencia está ligada siempre al Misterio de Dios. Si no reconoce su condición de “imagen” permanecerá en la ignorancia acerca de quién es él, cuál es el sentido de su vida en la tierra y cuál es su auténtico destino: el misterio no está sólo del lado de Dios, sino también del hombre que no se conoce sino en Dios. Valde profundus

\footnotetext{
50 Cfr. De Lubac, H., Le mystère du Surnaturel, 114.

51 Cfr. De Lubac, H., Le mystère du Surnaturel, 91; «Petite Catéchèse», 216-217.

52 De Lubac, H., Le mystère du Surnaturel, 161.

53 Cfr. De Lubac, H., Surnaturel, 491.

54 De Lubac, H., Le mystère du Surnaturel, 257.

55 Cfr. De Lubac, H., Le mystère du Surnaturel, 259.
} 
est ipse homo ${ }^{56}$. La revelación y la gracia llevan al hombre a descubrir este misterio que es él mismo.

De las explicaciones de $\mathrm{H}$. de Lubac se puede extraer que el hombre está llamado al fin que es Dios pero que sin Dios no alcanza. Como ya decíamos, este fin no es un simple aumento de ser, sino que requiere un nuevo principio de vida, una acción de Dios que no se deduce del dinamismo espiritual del hombre, y que eleva al hombre que se ha entregado a la comunión de vida divina llevando a su fin su propio dinamismo espiritual también. Este principio de vida que es la acción gratuita de Dios a favor del hombre, hace al hombre hijo de $\operatorname{Dios}^{57}$. Es un principio "completamente otro" que aquella apertura constitutiva del ser espiritual del hombre a lo absoluto; y sin embargo, eso "completamente otro" se adapta a esta apertura y responde a ella; no le es algo extraño, sino que, aun sobrepasando la dinámica espiritual que significa esa apertura, realiza su fin ${ }^{58}$.

Se conjuga aquí el misterio de la gratuidad y la libertad de la acción de la gracia de Dios que no suplanta, sino que posibilita la acción libre del hombre, mediante su acción liberadora. En el ámbito del encuentro personal, sin perjuicio de la desproporción entre ellas, mediante la bondad divina, el hombre es afirmado en su ser y en su identidad cuando se entrega a Dios. Como afirma Agustín de Hipona: "una cosa es el espíritu del hombre, otra el Espíritu de Dios, aunque una vez dado, aquel devenga igualmente, en un sentido muy real, nuestro espíritu"59.

La comunión es tan honda que la acción de Dios en el hombre es divina, sin negar con eso la acción humana que realiza su criatura dejándose conducir por el mismo Dios. La comunión del hombre con Dios comienza ahora, por lo que el Espíritu divino es, en un sentido real, "del hombre", no por apropiación, sino por donación gratuita ${ }^{60}$. Podemos así comprobar una vez más que el deseo de Dios, no es simplemente impulso interior, sino también llamada e invitación a la comunión. No es la aper-

56 Cfr. De Lubac, H. Le mystère du Surnaturel, 259.

57 Cfr. De Lubac, H., Le mystère du Surnaturel, 114.

58 Cfr. Schillebeeckx, «L'instinct de la foi selon s. Thomas d'Aquin». Revue des sciences philosophique et théologiques 48 (1964), 400 ; en de Lubac, H., Le mystère du Surnaturel, 115-116.

59 De Lubac, H., Le mystère du Surnaturel, 121.

60 Cfr. De Lubac, H., Le mystère du Surnaturel, 114. 
tura a un infinito innominado, sino al Dios personal, creador y salvador. Es apertura a Dios amor, al encuentro, a la relación, al vínculo a que Dios llama a su criatura y para la cual la creó.

\section{IMAGO TRINITATIS}

Que De Lubac recurra al concepto antropológico "imagen de Dios" como fundamento de su teología, nos lleva a preguntarnos qué imagen de Dios está a la base de su reflexión. Nuestro autor nos dirá que ser "imagen de Dios", en el sentido que hemos descrito, no es coherente solo con la idea de un Dios abstracto (causa de la naturaleza), sino con aquella del Dios caridad ${ }^{61}$ : "Dios es el Amor en persona, Amor que, sin ley ni determinación interna, suscita el ser al cual se quiere donar, y se da libremente" 62 .

Un Dios que es misterio de caridad y relación de personas da la clave para comprender qué significa el hombre creado a "imagen de Dios". En Catholicisme, De Lubac presenta al hombre en tanto persona, es decir, sujeto abierto a la relación. El fundamento de esta cualidad del ser del hombre es Dios Trinidad. En Dios encontramos la diversidad y la unidad y, más precisamente, la diversidad en vista a la unidad y la unidad que contiene la diversidad. Los seres espirituales reflejan en su ser, siempre analógicamente, la realidad personal de Dios, pues son imagen de Dios. De esta manera, De Lubac ve que en el hombre, espíritu creado a "imagen de Dios", se constata la "estructura" divina, pues en Dios no hay soledad, ni egoísmo, sino fecundidad e intercambio de Vida: "Lejana imitación del Ser, el espíritu creado no reproduce menos algo de su estructura - ad imaginem fecit eum - y una mirada experta sabe percibir la marca de la Trinidad Creadora" ${ }^{63}$.

La imagen en el hombre es "una lejana imitación" de Dios y su ser trinitario, es decir, es imagen de un ser personal ${ }^{64}$. De Lubac deja siempre clara la transcendencia de Dios. Sin embargo, siendo la creación fruto

${ }^{61}$ Cfr. De Lubac, H., Le mystère du Surnaturel, 155. Se puede confrontar a este respecto el comentario que el P. Huby hace a De Lubac en relación a las críticas que recibe por Surnaturel a fines de los 50's (cfr. de Lubac, H., Mémoire, 65).

62 De Lubac, H., Le mystère du Surnaturel, 288.

63 De Lubac, H., Catholicisme, 288.

64 Cfr. De Lubac, H., Sur les chemins de Dieu, 164-165 ; cfr. V. Franco, Le paradoxe du désir de Dieu, 274. 
del acto de amor por el que Dios se da otorgando el ser, en el hombre se imprime la imagen divina por la que es constituido espíritu, es decir, un ser abierto a Dios. Entonces podemos decir que el deseo del fin presente en el hombre está inscrito en él como consecuencia de haber sido creado a imagen del Dios personal, lo cual hace de su existencia una llamada a realizarse en el encuentro personal con su Creador ${ }^{65}$.

\section{IMAGo Christi}

Cuando se habla del pensamiento de $\mathrm{H}$. de Lubac, parece una afirmación común el débil desarrollo de la cristología ${ }^{66}$. Aun así, la referencia de su pensamiento al Verbo resulta clave y, más aún, la reclama ${ }^{67}$. Algunas pocas frases recogidas de la obra acerca de lo Sobrenatural nos llevan a esa convicción: no existe en Dios otra idea, o modelo, o forma, o razón de las cosas que el Verbo, el Verbo único que procede del Padre ${ }^{68}$. Todo el "mundo inteligible" está en Él condesado y Él procede del Padre y vive en su seno ${ }^{69}$. Sin embargo, debemos ampliar la búsqueda más allá.

65 Un texto lubaciano posterior al Concilio Vaticano II nos puede ayudar: «c'est que ce mystère de la Trinité nous a ouvert une perspective nouvelle: le fond de l'Être est communion» (De Lubac, H., La foi chrétienne. (Paris: Aubier-Montaigne. 1970), 13 14).

66 Cfr. García, D. «Conocer a Dios» 390. El autor lo muestra en las páginas inmediatamente anteriores, en relación a Sur les chemins de Dieu. En efecto, de Lubac mismo reconoció que no tuvo el coraje para redactar una obra sobre Cristo, a pesar de que ha estudiado el tema y reflexionado sobre él (cfr. De Lubac, H., Mémoire, 151; cfr. J-P Wagner, La théologie fondamentale selon Henri de Lubac. (Paris : Cerf. 1997), 67 ; F-X Nguyen Tien Dung, La foi au Dieu des chrétiens, gage d'un authentique humanisme. (Paris: Desclée. 2010), 244-245).

67 O'Sullivan sostiene que la respuesta lubaciana al problema de lo Sobrenatural tiene base cristológica (cfr. O’Sullivan, «Henri de Lubac's Surnaturel: An emerging christology». Irish Theological Quarterly 72 (2007), 3-31); y S. Wood que la paradoja, tan característica del pensamiento lubaciano, tiene su modelo en el misterio de la encarnación y la redención, es decir, tiene matriz cristológica (S. Wood, «The nature-grace problematic within Henri de Lubac's Christological paradox», Communio 19 (1992), 389-403).

Cfr Persidok, A., 15-16. «Primacía del Mediador. El hombre y Cristo en la teología de Henri de Lubac». Scripta Theologica 48 (2016), 592-593).

68 Cfr. De Lubac, H., Le mystère du Surnaturel, 283.

69 De Lubac, H., Le mystère du Surnaturel, 284. 
El punto clave de esta comunión es la encarnación redentora donde se realiza definitivamente aquella comunión de Dios y su criatura. En ella el hombre puede alcanzar, o mejor, recibir la unión divina para la que fue creado. Todos los deseos del hombre, dirá nuestro autor, se dirigen a un único Término, al abrazo de Dios en Cristo $^{70}$. En la admiración del misterio del Dios hecho hombre, el hombre mismo contempla y puede acoger el misterio de su propia identidad y el sentido de su existencia y de todo lo creado ${ }^{71}$.

La existencia del hombre "imagen" tiene unidad y sentido en Cristo. Y no solo como una realidad exterior y más allá del hombre que pueda dar valor a su vida e historia, sino porque el hombre está interiormente modelado en Cristo y en vistas al encuentro con Cristo ${ }^{72}$. La identidad del hombre es crística. Que Él sea quien revela al hombre su propia identidad, no significa que el encuentro con Cristo sea solamente una iluminación de lo que el hombre ya tiene en sí mismo o puede desplegar, sino que el encuentro y unión con Cristo representa una novedad transformadora para el hombre. El hombre recibe a Cristo como aquel en quien se cumplen todas sus aspiraciones y, al mismo tiempo, en quien es superado todo lo que el hombre puede esperar y suponer, pues en Cristo se da, concretamente en la historia y la existencia del hombre, aquel nuevo principio $^{73}$ que es más que un aumento de ser, que es la novedad del don que realiza la participación del hombre en la vida divina ${ }^{74}$. Es posible ver aquí la paradoja del hombre y su clave en la encarnación ${ }^{75}$ :

70 Cfr. De Lubac, H., Catholicisme, 186.

71 Cfr. De Lubac, H., Le mystère du surnaturel, 172.

72 Una cita en Le mystère du Surnaturel a este respecto es interesante: "Comme disaient les pères grecs, le Logos incarné recueille les «semences» déposées par le Logos créateur. Les latins disaient autrement que l'homme, image de Dieu, est, comme tel, apte à entrer en communion avec Lui, dans la liberté de l'esprit et la gratuité de l'amour» (M-D Chenu, La parole de Dieu. L'Évangile dans le temps. Paris: Cerf, 1964, 676; en De Lubac, H., Le mystère du Surnaturel, 16-17).

73 Cfr. De Lubac, H., Le mystère du Surnaturel, 114. Cfr. De Lubac, De Lubac, H., Le mystère du Surnaturel, 91 ; «Petite Catéchèse», 218.

74 Cfr. De Lubac, H., «Paradoxe et mystère de l'Église». En Euvres Complètes vol. IX. (Paris: Cerf, 2010). Reproducción de 1a ed. Paris: Aubier-Montaigne, 1967, 158159.

75 Cfr. S. Wood, «The nature-grace problematic», 401. 
Más allá de la redención propiamente dicha, comprendida como rescate del pecado y liberación del mal, el Verbo de Dios viene, tomando nuestra humanidad, a unirla a la divinidad. Criatura, el hombre no es Dios por esencia [...] Pero es creado "a imagen de Dios", y el Verbo de Dios da a todos los que "lo reciben", a todos los que "creen en su nombre [...] llegar a ser hijos de Dios" 76 .

De esta manera, el hombre creado a imagen de Dios encuentra en el Hijo eterno su identidad: ser hijo. La redención, que es la liberación del pecado, es la consumación de aquella vocación inscrita en el ser del hombre como "imagen de Dios" y es ser hijo en comunión con el Hijo, que, al ser siempre comunión con el Padre, nos introduce en la corriente de vida que es esa comunión en el Espíritu Santo: "Nosotros sabemos -y hay ahí de que llenarnos de estupor- que Dios se ha hecho hombre para que el hombre llegue a ser dios"77. Esta es la vida eterna anunciada por Jesucristo y que consiste en la visión de $\operatorname{Dios}^{78}$.

La "visión beatífica" [...] es una participación íntima en la visión que el Hijo tiene del Padre en el seno de la Trinidad. Haciéndonos conocer en su Hijo al Dios de amor, Dios personal y trinitario, Dios creador y salvador, el Dios "que se hace hombre para hacernos dios", la revelación cambia todo ${ }^{79}$.

La dinámica de este encuentro tiene su clave también en el Misterio Pascual. En efecto, el dinamismo espiritual del hombre, del que ya hemos hablado, es un dinamismo crístico. Todo el misterio de Cristo, dice De Lubac, es un misterio de resurrección, y por eso mismo de muerte. De ahí que el cristiano desemboque en cualquier reflexión en la contemplación del misterio de la Cruz y de la Pascua. Aquí encontramos toda la alquimia del ser, de la cual nadie puede escaparse ${ }^{80}$.

En Cristo el hombre puede reconocer su vocación y puede descubrir juntamente el don y el camino por el que alcanza la plenitud, que es la comunión con Dios a la que está llamado. El hombre reconoce en Cristo

76 De Lubac, H., «Révélation divine», en CEuvres Complètes vol. IV (Paris: Cerf, 2006), 35-231. Reproducción de 3a ed. revue et augmentée, coll. Traditions chrétiennes, (Paris, Cerf, 1983), 56.

77 De Lubac, H., Le mystère du Surnaturel, 172.

78 De Lubac, H., Le mystère du Surnaturel, 275.

79 De Lubac, H., Le mystère du Surnaturel, 280 ; cfr. 171-173.

80 Cfr. De Lubac, H., Catholicisme, 322. 
este llamado y el camino a esa comunión la cual no niega, sino que confirma y lleva a la plenitud la persona de cada hombre. Pero el hombre no accede a esa plenitud, sino muriendo por la entrega total de sí mismo al Señor:

Cristo nos acaba a todos, pero en Dios. Se puede decir [...] que nosotros no somos plenamente personales sino al interior de la Persona del Hijo, por la cual y en la cual nosotros tenemos parte en los intercambios de la vida Trinitaria ${ }^{81}$.

Por fin, la imagen de Dios personal, del océano de libertad y amor infinito que es Dios, imagen que se conoce por la revelación, nos muestra que la diferencia o distancia de Dios con su creatura se salva en la gratuidad del amor divino, que suscita la respuesta de amor de la criatura ${ }^{82}$. Ser capax Dei no es primero poder amar a Dios, sino ser amado por Él, dejarse llenar por su amor transformante.

\section{Conclusión}

El breve recorrido por el pensamiento de Henri de Lubac en torno a lo Sobrenatural nos permite afirmar que en este pensamiento se advierten los elementos de una antropología fundada sobre la idea del hombre creado a imagen de Dios. Es importante señalar, en primer lugar, que es criatura en tanto que su origen es el acto creador y su "seguir siendo" se comprende por la bondad de Dios que lo sostiene en la existencia. Su naturaleza creada no es una más entre todas, sino que es naturaleza espiritual, es decir, proyectada más allá de sí misma. Esta proyección no es apertura a un infinito indeterminado, sino es una destinación que le es ontológica: el encuentro con Dios. Origen y fin vinculan al hombre imagen a su Modelo y hacen que el misterio de su ser hombre no alcance su plena luz sino en el misterio de Dios.

El ser imagen significa que el hombre goza de autonomía. El hombre está llamado al encuentro con Dios. No puede alcanzarlo por sí mismo, pero puede rechazarlo. Dicho encuentro es posible por la acción gratuita de Dios que posibilita la libre entrega y abandono del hombre en Dios. Así se describe la dinámica según el binomio imagen - semejanza: es la dinámica espiritual del hombre. Esto lleva a pensar en la imagen de Dios que existe a la base. Ser imagen de Dios de esta forma solo se entiende en

81 De Lubac, H., Catholicisme, 298

82 Cfr. De Lubac, H., Le mystère du Surnaturel, 268-269. 
relación al Dios caridad, el Dios de la revelación. Aunque De Lubac no desarrolle prolijamente este aspecto del misterio de lo Sobrenatural, en especial cuando pensamos en la cristología, hay diversos elementos en sus escritos que convergen a poder afirmar que es el Dios de Jesucristo, y no otro, el que está a la base del pensamiento lubaciano. El hombre en De Lubac es imagen de Dios Trinidad, encuentra la clave de su propio misterio en el Verbo encarnado. 